\title{
Investigação sobre os Espaços Internos de Residências Modernaş a partir de Simulações Digitais de Ambientes
}

Research on Modern Indoor Spaces Houses from Digital Simulation Environments

\author{
> Wilson Florio \\ Universidade Presbiteriana Mackenzie \\ wflorio@uol.com.br
}

\author{
$>$ Ana Tagliari \\ Universidade Estadual de Campinas \\ anatagliari@hotmail.com
}

\begin{abstract}
This article investigates modern unbuilt houses designed by Vilanova Artigas and Carlos Cascaldi in Sao Paulo. The results indicate peculiar indoors features of these residences. Starting from scanned original drawings it was possible to produce 3D geometric models, and the simulation of the materials appearance in the interior spaces of these houses. The programs of these six residences are organized in half-levels, ramps, double height, inner courtyard, zenithal lighting and structural solution defining architecture. The goal is to investigate through renderings and walkthroughs in animations how the architects defined the internal spaces, establishing connections and visual-spatial continuity between floors.
\end{abstract}

Keywords: Simulation; Unbuilt; Rendering; Animation; Artigas

\section{Introdução}

Este artigo é resultado de uma pesquisa concluída sobre as residências urbanas náo construídas de Vilanova Artigas e Carlos Cascaldi em São Paulo. Os resultados obtidos indicam características peculiares dos ambientes internos destas residências. A partir da pesquisa documental no acervo digital da Faculdade de Arquitetura e Urbanismo da Universidade de São Paulo foi possível realizar experimentaçóes com modelos geométricos $3 \mathrm{D}$, com a simulação da aparência dos materiais nos espaços internos das residências estudadas. $\mathrm{O}$ critério de seleção das seis residências não construídas se pautou pelo fato de apresentarem as seguintes características: 1 . Organizaçáo do programa em meios -níveis; 2. Adoção de rampas como elemento de circulação vertical; 3. Pé-direito duplo e conformação de pátio interno; 4. Iluminação zenital sobre a rampa e/ou pátio interno; 5 . Solução estrutural como definidora da arquitetura. O objetivo é investigar como os arquitetos definiram e materializaram, na prática projetual, a sociabilização dos espaços internos, uma vez que a amplitude do pátio interno, e a rampa como elemento de conexáo e de continuidade espacial entre diferentes níveis de pavimentos, permitiram gerar espaços democráticos, cuja ênfase é o fortalecimento do convívio entre indivíduos.

A contribuição original desta pesquisa é analisar residências não construídas, desconhecidas dos pesquisadores em publicaçôes brasileiras, a partir de simulaçóes digitais estáticas e dinâmicas. A investigação destes espaços de sociabilização foi realizada por meio de simulaçóes estáticas, isto é, renderizaçóes, e simulaçóes dinâmicas, animaçóes, permitindo visualizar a conexão espacial entre diferentes espaços durante o percurso virtual.
As pesquisas consultadas (Ojeda, 1996; Novitski, 1998; Foscari, 2010) normalmente tratam de simulaçôes de edifícios históricos, de desempenho, fotorrealísticas ou relacionadas às técnicas empregadas no cinema. Esta pesquisa emprega as simulaçóes para investigar projetos não construídos de residências. Pesquisas anteriores como as realizadas por Bob Martens e Herbert Peter, "The Destroyed Sunagogues of Vienna", ou a de Kent Larson, "Louis I. Kahn: Unbuilt Masterworks", demonstram a importância das simulaçóes digitais como método de investigaçáo de projetos importantes que, infelizmente, não foram construídos, ou destruídos ao longo da história. $\mathrm{Na}$ ausência da construção de um edifício, a simulação computacional se torna um recurso fundamental para a compreensão da proposta do arquiteto.

As etapas de realização desta pesquisa foram as seguintes: 1 . Interpretação e análise dos desenhos digitalizados do acervo digital; 2. Modelagem geométrica dos elementos arquitetônicos; 3. Separação dos elementos construtivos de acordo com os materiais a serem simulados; 4. Importação da modelagem no 3DSMax; 5 . Inserção de luzes e de câmeras; 6. Aplicação dos materiais às superfícies dos objetos; 7. Simulaçôes estáticas, isto é, renderizações, de diferentes ângulos dos espaços internos e externos; 8. Produção de simulaçôes dinâmicas, ou seja, animaçôes, com o deslocamento do observador virtual a partir de percursos e trajetórias (paths) determinados.

\section{Método e Procedimentos Adotados}

A primeira etapa da pesquisa consistiu na interpretação dos dados contidos nos projetos selecionados. A primeira constataçáo é 
que apenas uma parcela dos desenhos produzidos pelos arquitetos foi digitalizada. Não foi possível acessar os desenhos originais. Estes fatos causaram dificuldades na interpretação, pois além da má qualidade dos desenhos digitalizados, náo foi possível obter todos os dados para a modelagem.

Em decorrência das dificuldades iniciais, iniciou-se ampla investigação sobre os edifícios construídos, de modo a completar informaçôes e conhecimentos sobre as residências concebidas no mesmo período. Foi possível interpretar o desenho das esquadrias em outros projetos dos arquitetos, construídos ou não.

Este procedimento se mostrou eficaz, na medida em que se pode constatar que os arquitetos adotaram soluçóes similares para a definição de alguns elementos construtivos, como esquadrias (portas e janelas), aberturas zenitais, muros de divisa, desenho de rampas, guarda-corpos e materiais empregados.

$\mathrm{Na}$ segunda etapa da pesquisa foi realizado o redesenho inicial de cada projeto no programa Rhinoceros. A escolha deste programa se deu em função de alguns objetivos. Como há intenção de produzir modelos físicos por prototipagem rápida, utilizando impressora 3D, assim como produzir desenhos bidimensionais para serem enviados para a cortadora a laser, este programa seria recomendável. A modelagem sólida da topografia e dos elementos construtivos atenderá a produção de modelos físicos também pela máquina $\mathrm{CNC}$.

A modelagem sólida no Rhinoceros foi parcialmente produzida com o auxílio da modelagem paramétrica de elementos construtivos no plugin Grasshopper (Figura 1, abaixo). Os caixilhos das janelas, os batentes das portas, escadas e guarda-corpos foram gerados parametricamente. Este procedimento acelerou a produção de elementos construtivos das seis residências modeladas. A partir de desenhos obtidos no acervo digital, foi possível identificar características nos elementos construtivos, particularmente nas esquadrias, escadas e domos. Este fato incentivou a criação de algoritmos para a produção destes elementos construtivos.

$\mathrm{Na}$ terceira etapa procurou-se separar os elementos construtivos de acordo com os materiais a serem empregados. Devido à falta de informaçóes, sobretudo da aparência dos materiais (cor, textura, acabamento, etc.), foi necessário recorrer a projetos similares, realizados no mesmo período, de modo a extrair conhecimentos sobre cada elemento construtivo, desde estrutura e vedaçôes até esquadrias e espaços livres. Foram identificadas algumas características no modo de designar os materiais. Por outro lado, constatou-se que os arquitetos não estabeleceram uma estratégia rígida para determinar os acabamentos dos materiais empregados. Apenas para citar um exemplo, percebeu-se que o concreto nem sempre ficava exposto, pois às vezes recebia pintura. As cores primárias preferidas eram amarela, azul e vermelha, complementados pelas cores neutras (branca, cinza e preta). Embora estas cores contribuíssem conceitualmente para a definição de ambientes, elas foram empregadas em diferentes setores das residências, ora no setor social, ora no setor íntimo ou de serviço.

O concreto aparente estava normalmente presente nas residências, sobretudo nas colunas, lajes e vigas. Mas as marcas das tábuas de madeira nem sempre eram deixadas ao natural. Às vezes
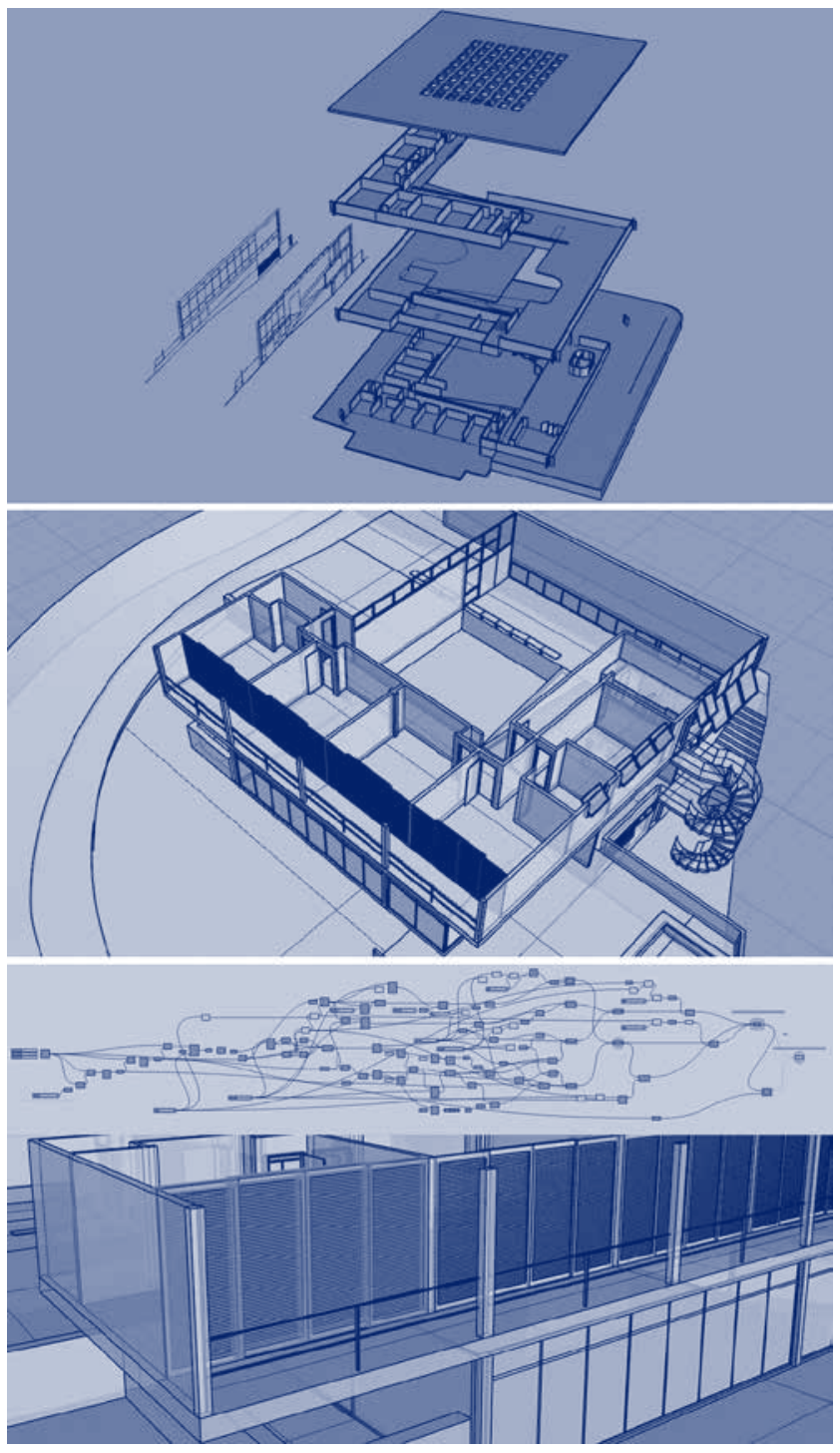

Figura 1: Modelagem sólida e paramétrica das Residências Jorge Edney Atalla (1971) e José David Vicente (1959), ambas não construídas. Fonte: Wilson Florio e Ana Tagliari, 2014.

eram revestidas por argamassa na cor branca. Estes fatos indicam que, aparentemente, tais definiçóes de materiais variavam de acordo com a percepção pretendida para o espaço, dependia de suas dimensôes, e muitas vezes era uma definiçãao que era realizada no próprio canteiro de obras, como bem declarou um dos arquitetos ${ }^{1}$ que trabalhou com Artigas.

Entre a quarta e sexta etapa da pesquisa, ocorreram ensaios sobre a aparência dos materiais e iluminação natural / artificial dos ambientes internos. Para isso foi utilizado o programa 3DSMax, que contém recursos compatíveis com aqueles pretendidos pela

1 O arquiteto Cleber Machado trabalhou com Vilanova Artigas durante 10 anos. Em depoimento pessoal, ele declarou que, embora houvesse um projeto executivo, o arquiteto definia também os acabamentos dos materiais diretamente no canteiro de obras, de acordo com aquilo que avaliava durante a construção. 
pesquisa. Neste programa gráfico foi possível gerar imagens com a definição desejada, e produzir passeios virtuais pelos espaços conectados por rampas. Assim, simulações estáticas, renderizaçôes de determinados pontos fixos no espaço, e simulaçóes dinâmicas, walkthrough, foram realizados com a intençâo de investigar as características e a qualidade dos espaços internos das residências investigadas. A sexta etapa foi a mais experimental, pois diferentes materiais, níveis de iluminação foram testados.

Após testar diferentes configuraçóes, de materiais, texturas e cores, foram selecionadas as alternativas mais condizentes com os conceitos identificados nas obras construídas. Assim, na sétima etapa foram produzidas imagens de pontos vista internos e externos, de modo a investigar a qualidade e as características espaciais destes espaços.

É importante destacar que a integração espacial e a fluidez de espaço foram particularmente os pontos principais desta avaliação. Com será visto adiante neste artigo, de fato havia grande preocupação com os espaços de sociabilização.

$\mathrm{Na}$ etapa final foram produzidas animaçóes. Estas simulaçóes dinâmicas permitiram identificar como os ambientes internos eram percebidos durante o tempo de deslocamento do observador num dado percurso no espaço.

\section{Análise da Residência H. Villaboim (1966)}

Nesta residência, proposta para um bairro nobre da cidade de Sáo Paulo, os arquitetos criaram uma residência com volumetria e geometria regular. $\mathrm{O}$ terreno de meio de quadra é formado por um acentuado aclive. Os vários meios-níveis propostos facilitam o escalonamento dos pavimentos.

O acesso social e de serviço ocorre pelo nível mais baixo. Após a rampa que dá acesso à garagem de automóveis, pode-se entrar na área social por um pé-direito de $2,50 \mathrm{~m}$. Mas na sequência o usuário se defronta com um átrio central de pé-direito de $6,70 \mathrm{~m}$, com três lances de rampas que conectam os três pavimentos, dotado de iluminação zenital e amplas aberturas frontais (Figura 2).

Figura 2: Imagens capturadas durante a animaçáo da Residência Henrique Villaboim Filho (1966). Fonte: Wilson Florio e Ana Tagliari, 2014.
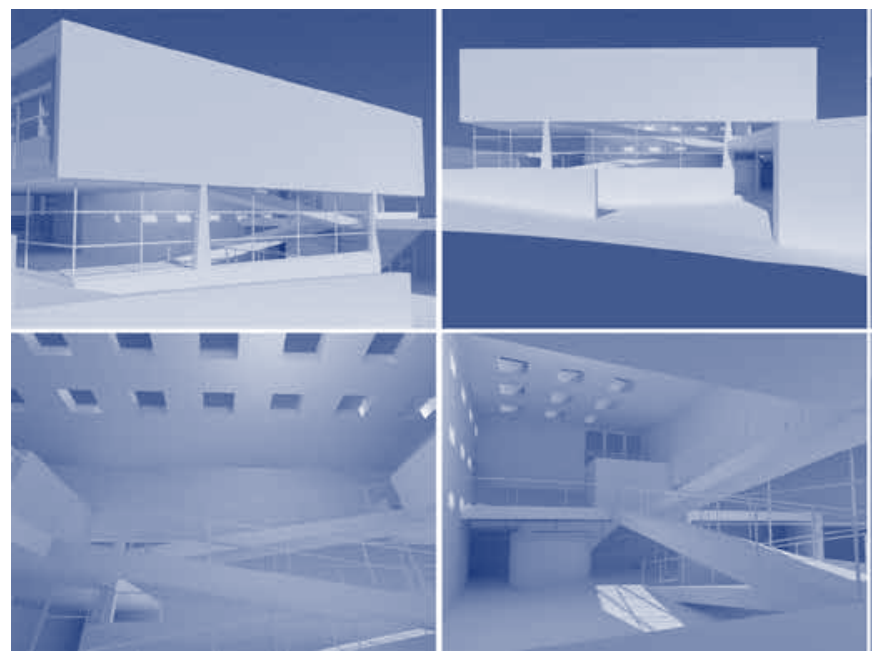

Como em outras residências projetadas pelos arquitetos, há fortes contrastes entre as empenas e paredes cegas e amplas aberturas envidraçadas. A ideia de "caixa de concreto armado", suspensa por pequenas colunas, é fortalecida pelo contraste entre a predominância de vidros no pavimento inferior e a empenas cegas no pavimento superior. Outra característica marcante nestas residências é a criação de dois núcleos de circulação: o social, por rampas, e o de serviço, por escadas.

As animaçóes produzidas facilitaram a interpretação e averiguaçáo dos conceitos declarados pelos arquitetos: espaços de encontro para a sociabilização. Isso ocorre por meio da conexão entre espaços por rampas, dispostos em meios-níveis, mas voltados para o generoso espaço interno do átrio. Ao contrário das residências formadas por pavimentos estanques, estas residências possuem características similares àquela adotada para o prédio da Faculdade de Arquitetura e Urbanismo da Universidade de Sáo Paulo, dos mesmos arquitetos. As rampas são locais de encontro casuais, o grande átrio permite a comunicação visual entre pessoas em vários pavimentos. A integraçáo é fortalecida, e a continuidade visual e espacial é garantida.

Embora as imagens renderizadas facilitem a investigação das qualidades e características espaciais dos ambientes não construídos, os percursos virtuais produzidos promovem a interpretação temporal nesta conexáo entre espaços em diferentes pavimentos. $\mathrm{O}$ walkthrough é um meio eficaz para averiguar aspectos funcionais, técnicos, estéticos e perceptivos de modo síncrono.

Nestas análises notou-se que os arquitetos projetaram as residências com grande preocupação com os percursos e sequências de espaços. Como um diretor cinematográfico, os arquitetos ordenaram os espaços de modo temporal, de modo a permitir a plena incorporação do conceito moderno de "promenade achitecturale", isto é, passeio arquitetônico.

Como é possível observar na Figura 2, há contraçôes e dilataçôes de espaços, proporcionado pelas variaçôes de pé-direito. Num primeiro momento as rampas induzem o olhar no sentido transversal. Mas durante o percurso "aéreo" do observador virtual, verificou-se que há diversos focos de interesse, como a penetração da luz superior, o contraste entre paredes cegas e envidraçadas, o
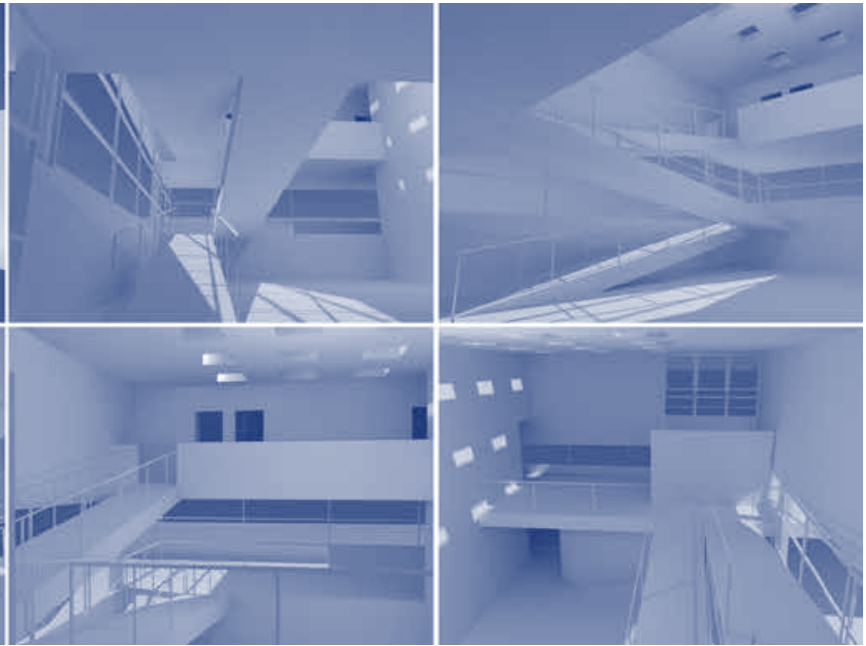
grande "vazio" do átrio central, que, juntos induzem o olhar em várias direçôes.

É importante destacar que nesta simulação, antes de testar materiais aos elementos arquitetônicos, procurou-se analisar a geometria e organização das formas no espaço. A pureza do branco acentua esta percepçáo, exaltando, com maior intensidade, o papel da luz natural nos ambientes internos. Vale ressaltar a impressionante continuidade espacial entre pavimentos, interligados por rampas suspensas.

\section{Análise da Residência J. D. Vicente (1959)}

Esta residência, projetada na cidade de Campinas, a $110 \mathrm{~km}$ de Sáo Paulo, seria implantada em lote de esquina, com topografia em aclive. A volumetria austera, num único volume retangular, abriga os setores social, íntimo e serviço em três pavimentos. Organizado em meios-níveis, os pavimentos são conectados por rampas junto ao pátio interno, com pé-direito alto, dotado de iluminação zenital. A expressão arquitetônica se dá por meio da concepção da estrutura, formando uma "caixa" suspensa, sustentada por pilares delgados.

O rigor geométrico da disposição da estrutura independente, de concreto armado expressa, com nitidez, as modulaçóes de vigas e lajes. Na relação entre os espaços internos e externos, há fortes contrastes entre as empenas cegas e as aberturas envidraçadas. Porém, os espaços internos são generosos, sobretudo nas áreas sociais, dispostas em dois pavimentos conectados por rampas. A configuração de um átrio central, banhado de luz zenital, gera um espaço hierárquico importante, que fortalece o sentido de espaço de encontro e de convergência do núcleo familiar. Além disso. as circulaçóes no último pavimento se voltam para este átrio, proporcionando continuidade espacial e integração visual.

Os espaços sociais no pavimento térreo alternam pés-direitos altos e baixos, e se conectam aos espaços externos por amplas aberturas envidraçadas, que geram continuidade espacial entre o interior e o exterior da casa. Vale salientar que os arquitetos voltaram as aberturas para quadrantes adequados de insolação, e dotados de boas visuais do entorno imediato. As áreas livres do terreno integram-se às calçadas, sem delimitaçóes rígidas, criando uma continuidade entre o espaço público e o espaço privado.

A grande vantagem da criação de um modelo geométrico digital 3D é poder gerar percursos virtuais por tais espaços.

$\mathrm{Na}$ simulação dinâmica de um observador virtual em movimento, a câmera percorre uma trajetória preestabelecida. Esse processo é normalmente denominado walkthrough, ou seja, caminhar através do espaço.

\section{Conclusões Finais}

Os autores concluem que estes recursos digitais ampliaram as possibilidades de interpretação da qualidade e das propriedades dos espaços internos de projetos não construídos destes importantes arquitetos brasileiros, assim como para a análise da sequência temporal dos espaços concebidos, incluindo variaçóes de pé-direito e diferentes visuais entre espaços internos e/ou externos.

Consequentemente, as animaçóes permitiram obter a sensação provocada por espaços integrados. Além disso, os modelos
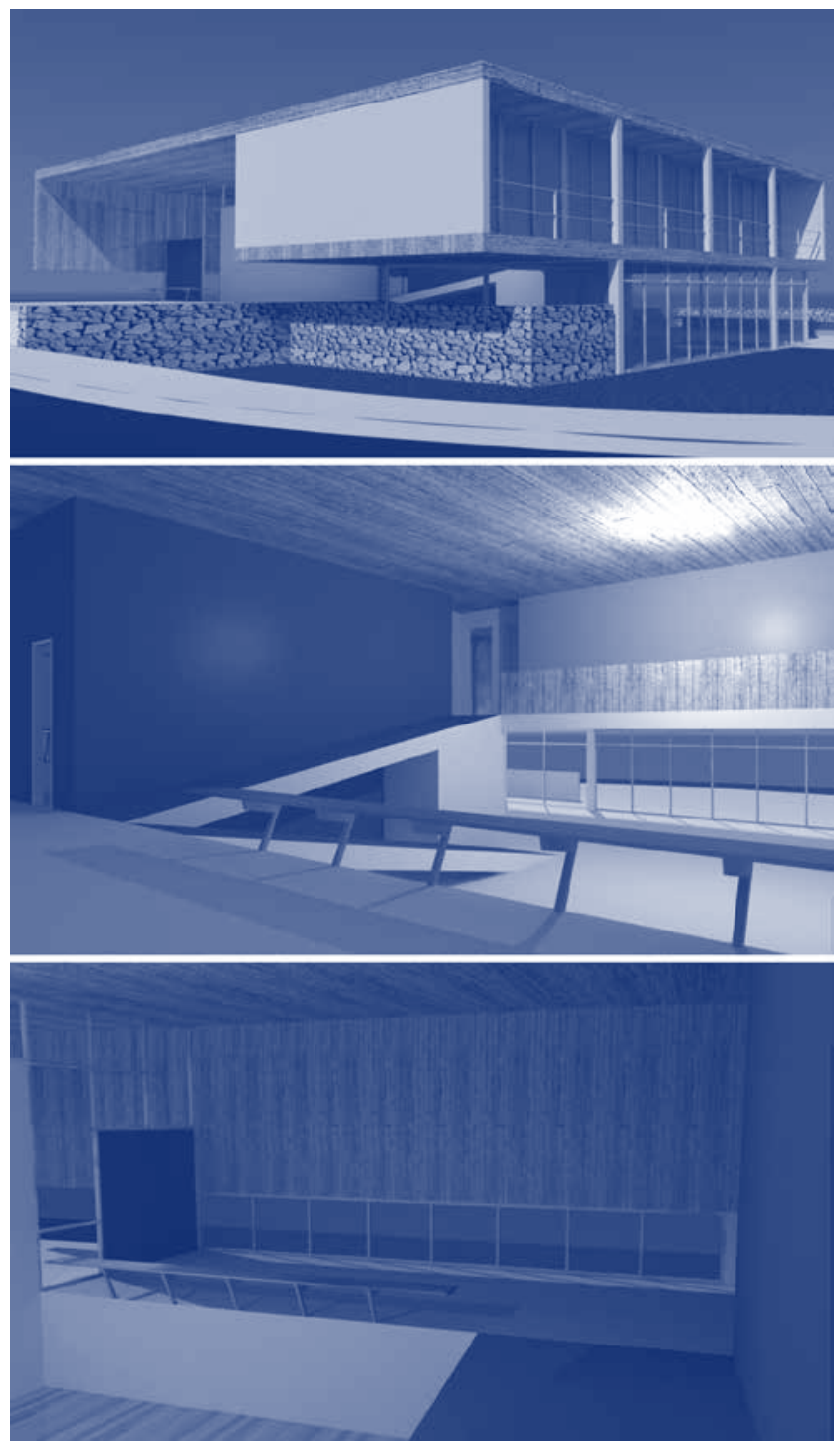

Figura 3: Imagens renderizadas da Residência não construída José David Vicente (1959). Fonte: Wilson Florio e Ana Tagliari, 2014.

geométricos digitais 3D possibilitam testar e simular uma série de aspectos e características do espaço projetado ao mesmo tempo, antecipando aspectos percebidos na realidade construída. Nesse sentido, foi possível analisar sincronicamente aspectos estéticos, técnicos e perceptivos relativos às propriedades do edifício.

De fato, os projetos estudados contêm a ideia do pátio interno, como elemento articulador, e das rampas como elementos de conexáo espacial. Estes conceitos ficaram evidentes durante a interpretação auxiliada por simulaçóes digitais, demonstrando a concretização dos conceitos defendidos pelos autores dos projetos.

O pé-direito duplo, o pátio e as rampas proporcionam a continuidade visual e espacial na casa entre os setores social, íntimo e estúdio. As imagens produzidas destes espaços internos, com a simulação dos materiais e da luz direta e difusa, permitiram a interpretaçáo da qualidade e caraterísticas destes projetos que não foram edificados. 


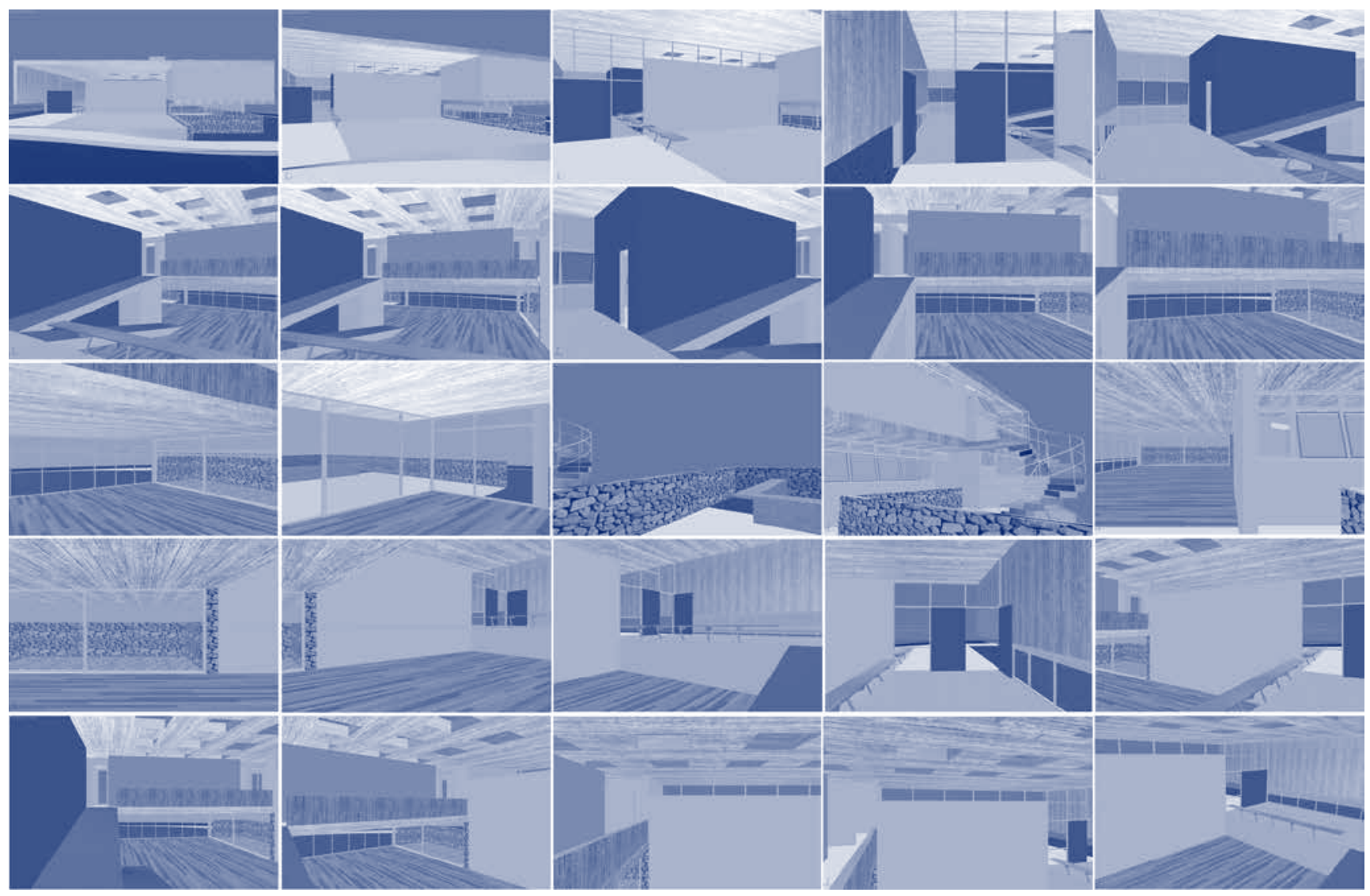

Figura 4: Frames parciais da animaçáo de dois minutos da Residência José David Vicente. Fonte: Wilson Florio e Ana Tagliari, 2014.

\section{Agradecimentos}

Os autores agradecem o apoio financeiro do CNPq.

\section{Referências}

Foscari, A. (2010). Andrea Palladio. Unbuilt Venice. Baden: Lars Muller Publishers.

Larson, K. (2000). Louis I. Kahn. Unbuilt Masterworks. New York: The Monacelli Press.
Martens, B., \& Peter, H. (2012). The Destroyed Synagogues of Vienna. Münster: LIT Verlag GmbH.

Novitski, B. J. (1998). The art of Computer Modeling from the Palace of Kublai Khan to Le Corbusier's Villas. Massachusetts: Rockport Publishers.

Ojeda, O. R., \& Guerra, L. H. (1996). Hyper-Realistic. Computer generated architectural renderings. Massachusetts: Rockport Publishers / McGraw Hill. 